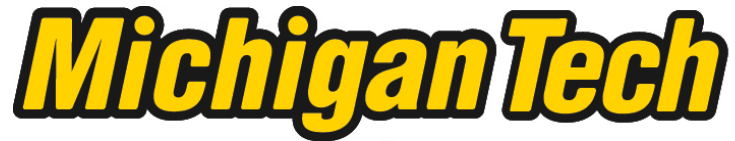 \\ Michigan Technological University Create the Future Digital Commons @ Michigan Tech
}

Dissertations, Master's Theses and Master's Reports - Open

Dissertations, Master's Theses and Master's

Reports

2014

\section{A REPORT ON THE MITEP PROGRAM AND ITS IMPACT ON MY TEACHING}

Nicholas C. Grabemeyer

Michigan Technological University

Follow this and additional works at: https://digitalcommons.mtu.edu/etds

Part of the Science and Mathematics Education Commons

Copyright 2014 Nicholas C. Grabemeyer

\section{Recommended Citation}

Grabemeyer, Nicholas C., "A REPORT ON THE MITEP PROGRAM AND ITS IMPACT ON MY TEACHING", Master's report, Michigan Technological University, 2014.

https://doi.org/10.37099/mtu.dc.etds/883

Follow this and additional works at: https://digitalcommons.mtu.edu/etds

Part of the Science and Mathematics Education Commons 
Nicholas C Grabemeyer

\author{
A REPORT \\ Submitted in partial fulfillment of the requirements for the degree of \\ MASTER OF SCIENCE \\ In Applied Science Education \\ MICHIGAN TECHNOLOGICAL UNIVERSITY \\ (C) 2014 Nicholas C Grabemeyer
}


This report has been approved in partial fulfillment of the requirements for the Degree of MASTER OF SCIENCE in Applied Science Education.

Department of Cognitive and Learning Sciences

$\begin{array}{cc}\text { Report Advisor: } & \text { Bradley H Baltensperger } \\ \text { Committee Member: } & \text { Kedmon N Hungwe } \\ \text { Committee Member: } & \text { William I Rose } \\ \text { Department Chair: } & \text { Susan Amato-Henderson }\end{array}$




\begin{abstract}
This report has two major objectives. First, the results of an action research project conducted at my high school concerning the use of graphic organizers and their effects on students' written expression abilities. The findings from this action research project indicate that the use of graphic organizers can prove beneficial to students. The second major objective of this report is to provide a reflection and evaluation of my experiences as a participant in the Michigan Teacher Excellence Program (MiTEP). This program provided middle and high school science teachers with an opportunity to develop research based pedagogy techniques and develop the skill necessary to serve as leaders within the public school science community.
\end{abstract}

The action research project described in the first chapter of this report was a collaborative project I participated in during my enrollment in ED 5705 at Michigan Technological University. I worked closely with two other teachers in my building Brytt Ergang and James Wright. We met several times to develop a research question, and a procedure for testing our question. Each of us investigated how the use of graphic organizers by students in our classroom might impact their performance on writing assessments. We each collected data from several of our classes. In my case I collected data from 2 different classes over 2 different assignments. Our data was collected and the results analyzed separately from classroom to classroom. After the individual classroom data and corresponding analysis was compiled my fellow collaborators and I got together to discuss our findings. We worked together to write a conclusion based on our combined results in all of our classes. 


\section{Chapter One}

Action Research

ED 5705

\section{Michigan Technological University}

Brytt Ergang

Nick Grabemeyer

James Wright 


\section{Action Research for ED 5705}

\section{Motivation for the study}

We are motivated to conduct the study of the effectiveness of graphic organizers in regards to student performance for several reasons. First, our school in recent years has placed an emphasis on closing the achievement gap between our highest performing students and our lowest achieving students in all content areas but especially in writing. As a result our school has adopted several strategies aimed at improving students writing. One of the main strategies adopted by the school and incorporated into the school improvement plan was the use of graphic organizers. The graphic organizers that were selected specifically focused on helping students summarize, compare \& contrast, and sequence. We have been trying to incorporate them into my lesson plans but would like to know if they are helping to raise student achievement at all.

We know that the members of my school improvement team as well as building and district administrators would be interested to learn about the results our study. In addition, the other teachers who we work with in my building would benefit from knowing whether or not these strategies are worth doing with the students or if our time and effort might be spent better elsewhere in an attempt to close the achievement gap at our school.

\section{Research question}


The research question the group posed was an action based question. We wanted to know if using graphic organizers improved their written expression as measured by the quantity and quality of student writing samples.

\section{Readings about the study}

We have found that many others have done studies on the use of graphic organizers and student achievement and the studies show that students do benefit from the use of graphic organizers. Graphic organizers help students make relationships between related facts and concepts (Gil-Gracia \& Villegas, 2003). Studies have also shown that graphic organizers help students with reading retention (Ozmen, 2011). We want to see how our students writing assessments in science are affected by the use of graphic organizers prior to writing. Many of our students have a difficulty answering questions in an essay format or performing well whenever they are asked to write. Hopefully with the use of a graphic organizer prior to a writing assessment students will be able to organize their thoughts and knowledge and answer questions in meaningful and correct manor.

\section{Research plan for the study}

The school this study is being conducted at is Kalamazoo Central High School. Kalamazoo Central is a large school with a student population of approximately 1600 students. The student body is diverse socially, culturally, economically, and ethnically. The grade level of the students in the study ranged from $9^{\text {th }}$ graders to $12^{\text {th }}$ graders; however, most of the students were $9^{\text {th }}$ graders.

We collected data from each of our classes for this study. We identified classes that served as controls and classes that served as experimental groups. The control 
classes were given a writing task for an assessment after having participated in a lesson related to the assessment. The experimental classes were given the same lesson, but before the writing task was given they were provided with a graphic organizer to complete. Then they were given the writing task. The writing assessments from both groups were then collected and scored based on the same rubric. This data was collected and analyzed to see if any statistical significant differences were found between the scores from the control classes and the scores from experimental classes.

One of our district's goals is to increase writing across the curriculum. We are doing this by using the Collins writings in all classes. Collins writings encourages students to think and to write through five different types of writing assignments (Type One through Type Five), which can be used in any content area.

In our study many students completed Type twos and Type threes that were used as our assessment evaluate how graphic organizers aided them in their writing. Type two writings demonstrate what the writer knows about a certain topic and is graded or is able come up with the correct answer to a question. Type three writings have more substance and the writers focus on at least three specific "Focus Correction Areas," FCAs. Simply put FCAs are the area that teachers want the students to concentrate on. These are the only points of the paper that are assessed. Student revisions should also be done on the same paper in Type three writings. More information on Collins Writing can be found at www.collinsed.com.

We used student documents as the source for our data. These documents consist of written assessments from 6 different science classrooms; each class had an average of 28 students. The writing task utilized graphic organizers by one class of 
students before they wrote their written responses, while another class of students did not use any type of organizer prior to their writing. Both sets of work were graded using a content standard. We were able to manage the collecting of student data over several weeks of school. By gathering data from several sources and selecting the type of data we are using in our study, we're confident that we have a good match between our source of data and our inquiry question, "Does student use of graphic organizers improve student achievement in written expression?"

We analyzed our data by making a comparison of student scores for the written assessments between the two test groups. We employed the t-test to determine if there's significance in our results that supports the use of graphic organizers to improve student performance in written expression.

\section{Analysis and Interpretation}

\section{Classroom A Results}

Investigator: Nick Grabemeyer

In this classroom, two sets of data were collected from two different assignments, in two different classes. Each class was the same course, just a different period. One assignment involved the students reading an article about symbiosis. One class was provided with a graphic organizer to complete while they read the article. The other class was not provided with the graphic organizers. Each class was then asked to summarize the article in writing. The following rubric describes the criteria I used to grade the student summaries.

\section{Rubric for Grading Symbiosis Summaries}




\begin{tabular}{|c|c|c|}
\hline 5 & All 5 requirements were met. & The summary should include the \\
\hline 4 & 4 requirements were met. & following: \\
\hline 3 & 3 requirements were met. & 1. General Definition of Symbiosis \\
\hline 2 & Only 2 requirements were met. & 2. Description of Parasitism \\
\hline 1 & Only 1 requirement was met. & 3. Description of Mutualism \\
\hline 0 & $\begin{array}{l}\text { None of the requirements were } \\
\text { met. }\end{array}$ & $\begin{array}{l}\text { 4. Description of Commensalism } \\
\text { 5. Examples of Symbiosis }\end{array}$ \\
\hline
\end{tabular}

The class results from this assignment are summarized below.

\begin{tabular}{|l|l|l|}
\hline & $\begin{array}{l}\text { Class 1 With graphic organizer } \\
\text { (22 Total Students) }\end{array}$ & $\begin{array}{l}\text { Class 2 Without graphic } \\
\text { organizer (26 Total Students) }\end{array}$ \\
\hline Mean $=$ & 4 & 3.38 \\
\hline $\begin{array}{l}\text { Standard } \\
\text { Deviation }=\end{array}$ & .87 & .94 \\
\hline $\mathrm{t}-$ test $(\mathrm{p})=$ & \multicolumn{3}{|l}{.02} \\
\hline Cohens $(\mathrm{d})=$ & \multicolumn{3}{|l}{.66} \\
\hline
\end{tabular}

The second assignment involved an article about human evolution. The same basic protocol was used. I provided students with the article. I gave one class of students a graphic organizer to complete while they read the article. I gave the other class nothing. After they finished reading the article I asked them to summarize the article in writing. The rubric I used to grade the student writing is below:

Rubric for Grading Human Evolution Summaries

\begin{tabular}{|c|c|c|}
\hline \multicolumn{2}{|r|}{ Score } & Requirements \\
\hline 5 & All 5 requirements were met. & The summary should include the \\
\hline 4 & 4 requirements were met. & following: \\
\hline 3 & 3 requirements were met. & 1. Overview of human evolution \\
\hline 2 & Only 2 requirements were met. & 2. Description of H. habilis \\
\hline 1 & Only 1 requirement was met. & 3. Description of H. erectus \\
\hline 0 & $\begin{array}{l}\text { None of the requirements were } \\
\text { met. }\end{array}$ & $\begin{array}{l}\text { 4. Description of } \mathrm{H} . \\
\text { heidelbergensis } \\
\text { 5. Description of } \mathrm{H} \text {. neanderthalis }\end{array}$ \\
\hline
\end{tabular}

The results from this assignment are summarized below: 


\begin{tabular}{|c|c|c|}
\hline & $\begin{array}{l}\text { Class } 1 \text { With graphic organizer } \\
\text { (27 Total Students) }\end{array}$ & $\begin{array}{l}\text { Class } 2 \text { Without graphic } \\
\text { organizer (26 Total Students) }\end{array}$ \\
\hline Mean $=$ & 3.93 & 3.38 \\
\hline $\begin{array}{l}\text { Standard } \\
\text { Deviation }=\end{array}$ & .83 & 1.02 \\
\hline $\mathrm{t}-$ test $(\mathrm{p})=$ & & .04 \\
\hline Cohens $(\mathrm{d})=$ & & .59 \\
\hline
\end{tabular}

I used the same two classes for each assignment, but I did switch which class got to use the graphic organizer and which class didn't. This was done to make sure that any differences found were due to the graphic organizers and not differences in the ability of the students in each class. The results show that the use of the graphic organizers prior to completing the writing assignments improved the average score for the class that got to use them.

A t-test was completed for each data set. The null hypothesis that was used for both was: the class that did not get a graphic organizer will not differ significantly from the class that did get to use the graphic organizers. According to the t-test results for both assignments the difference was statistically significant. The symbiosis writing assignment had a (p) of .02. The human evolution writing assignment had a (p) of .04. Both of these results are below the (p) of .05 which is considered to be the threshold of statistical significance. Therefore, the null hypothesis can be rejected, and the difference in the mean score between the classes is due to the use of the graphic organizers. Cohen's D effect sizes of .66 and .59 respectively indicate a moderate to high level of significance to these results.

\section{Anecdotal Observations}


While each class was completing their writing assignments I circulated around the room and observed how students were doing. I stopped and talked with students occasionally, answered questions, and clarified expectations when necessary. I noticed that the classes that were given the graphic organizers spent more time looking at the reading. In fact, I noticed many students who appeared to reread the articles more than once while they were filling out the graphic organizers. I did not notice that behavior nearly as often when observing the classes that did not get to use the graphic organizers. I also noticed that the classes that used a graphic organizer spent much more time with their writing than the classes who did not get to use a graphic organizer. Many of the students who did not have the graphic organizer to help them completed there writing in less than five minutes, whereas most of the students that had the graphic organizers spent much more than 5 minutes on the writing assignments. Some of them even had to be told to hurry up before they ran out of time.

\section{Classroom B Results}

Investigator: Brytt Ergang

In four Forensic Science classes students performed an experiment on identifying a mystery powder. After the students finished their labs they were asked to complete a lab write up using Collins Writing Type III format. They were evaluated on the following criteria or "Focus Correction Areas," FCAs:

1. Describe the procedures used in the lab.

2. Explain how they were able to determine their mystery powder

3. What other tests should be performed to confirm their decision. 
The total assignment was worth twenty points. Five points were given for correctly describing the procedures. Ten points were given for correctly identifying the mystery powder and giving reasonable explanation of their deductions and five points were given for explaining how different quantitative tests could be used to identify a specific drug's chemical makeup.

In my first two periods I had the students first fill out graphic organizers before doing their write ups. The graphic organizer I used was a Ladder graphic organizer. For the "Compare" section I asked to describe what they were comparing in the lab. The "List" section they were to list the procedures they used in the lab. In the "Decide" portion they were to simply put the identity of the mystery powder. The "Explain" portion they entered in their reasoning for making that determination of the mystery powder and finally the "Extension" component was what could be done to further to confirm your decision. The other two classes were not given a graphic organizer. They were given the same F.C.A.'s and the grades of the classes were then compared.

The grades were changed to percentages and a statistical analysis was performed comparing the two classes that used the graphic organizers to the two classes that did not. There were a total of 41 students that completed the assignment in the classes that used graphic organizers. The students that used the graphic organizers had an average grade of 76.6 and a standard deviation of 16.7. The classes that did not use graphic organizer 43 students completed their assignment and had an average grade of 61.6, with a standard deviation of 23 . With a T-Test value of 0.001 it fell well below the threshold of 0.05 . This indicates that there is a statistical difference 
between the two classes. With a Cohen's d effect size of 0.75 this indicates a moderate to high significance.

In two biology classes students read the article "What is Life" and then wrote a summary of the article. The summary was in Collins Writing Type III format with three points given for identifying the Author, article title, and source in their topic sentence. Four points were given for identifying the main ideas of the article and three points given for explaining the difference between living and biotic. One class was given "The Frame" graphic organizer and to fill in the appropriate boxes and the other class was not provided with the graphic organizer.

The grades were changed to percentages and a statistical analysis was performed comparing the two classes that used the graphic organizers to the two classes that did not. There were 15 students that used graphic organizers to complete their assignment. These students had an average of 79.3 and a standard deviation of 14.7. The classes that did not use graphic organizers had 17 students with an average of 63.9 and a standard deviation of 19.5. With a T-Test value of 0.01 it also fell well below the threshold of 0.05 . Once again, there is a statistical difference between the two classes with 0.96 for Cohen's d effect size showing a high practical significance.

The reason for there being a statistical different in the classes that used graphic organizers versus the classes that did not is that the graphic organizer seem to help students that would have performed extremely poorly on their writing assignments. In classes where graphic organizers were used most students that completed their assignments had no difficulty in meeting most of the requirements for the assignment. However, in the classes where graphic organizers were not used, a much larger 
student population fell before failing for the assignment. Both had students that performed well but the use of graphic organizers has aided in closing the gap between the high achieving students and the low achieving students that were aided with the use of a graphic organizer. Also I would like to note that in classes with graphic organizers more students did not complete their writing assignment and any assignments that were not handed in were included in this analysis.

\section{Classroom C Results Investigator: James Wright}

My data was collected from two 9th grades, high school Biology classes, referred to as class "A" and class "B". Each class of students produced a written summary after reading about a topic in Ecology and later about a topic from a unit on Evolution. In each case, prior to the reading and writing assignment, class " $\mathrm{A}$ " was provided with a graphic organizer to use and class "B" was not. A rubric was employed to grade the elements of the students written summaries. The summary was to be written in complete sentences, a minimum of 50 words and was to include 4 descriptive examples of main ideas. The comparative grades of these two classes for the written summaries serves as the data used to evaluate the effectiveness of using graphic organizers by students to improve their skills at writing topic summaries.

On the initial trial, the 2 different Biology classes were asked to read a section in their textbook that considered 5 types of interactions between species making up an ecological community. There were 22 students in attendance in class " $\mathrm{A}$ " and 12 students in class "B". Class "A" was provided with a graphic organizer in which they could record main ideas and supporting details. Class "B" was not. Both classes 
constructed a written summary, mindful of the grading rubric. The results for this first writing test showed an average mean score of 13.4 for class " $\mathrm{A}$ " having used an organizer before summarizing, compared with an average mean score of 12.3 for class "B". A t-test score of 0.60 does not indicate that the comparative difference between the mean score of the two classes is significant enough to suggest that the use of a graphic organizer could account for the difference in the scores of the written summaries between the two classes. The calculated Cohen's D size effect score for this trial has a value of 0.21 . This score suggests that the practical significance of this trial is small as defined by the magnitude difference value of 0.20 . The first time application of the graphic organizer prior to writing about science in my classroom may account for the small difference between the average mean scores for the written summaries of the two classes.

On the second trial, the 2 different Biology classes were presented with a similar summary exercise. There were 17 students in attendance for class " $A$ " and 21 students in class "B" at that time.. They were to read about numerous examples of evolutionary evidence. As before, each of the same classes was to write a summary that used a grading rubric similar to the previous one. The average mean score in written summaries increased slightly for the graphic group, from an earlier mean of 13.4 to 15.2. The t-test result of .03 for this assignment does indicate that the difference in scores between the two classes was statistically significant. The Cohen's effect size score of 0.41 for this result suggests a practical significance that approaches a moderate difference in magnitude with a value of 0.50 . 
This slight increase could be related to the favorable response expressed by some students towards the use of the graphic organizer, when incorporated in the reading and writing process. They like the purpose of the organizer and have become more familiar, comfortable and experienced with its application across our school curriculum. An increase in the average mean scores is very noticeable in the comparative results of 15.2 for the graphic using class to that of 12.08 for the class having never used a graphic organizer in our science class. The fact that there appears to be little change or increase in the summary score for this group from an earlier mean score of 12.3 to that of 12.1 suggests that the lack of use of graphic organizers by students could result in lower grades for written expression, as suggested by this comparative data.

\section{Conclusion}

In six assignments that were given the average grades of classes that used graphic organizers were higher than classes that did not use them. By using a t-test five of the six assignments had a statistical difference of improvement. The majority of the change was with the lower achieving students. When graphic organizers were used there were less low achieving students and less extremely low grades. With the use of graphic organizers we can conclude that graphic organizers can help close the gap between high and low achieving students.

The study did not identify students writing proficiencies. Future studies could track students' writings and determine how much they improve with the use of graphic organizers. Such a study could help determine how a graphic organizers benefits students with low, middle, and high end writing skills. In this study we were 
able to observe an increase in low achieving students but are unable to determine how much it helps. This study also does not show how the writing of middle and high end students improves if at all.

We believe that providing graphic organizers to students before asking them to write about what they read can be beneficial. It provides an opportunity for students to reflect on their reading and plan what they will write about. That extra step has been shown to make a difference in the performance of a writing task for the average student. In future studies it would be valuable to explore how the use of graphic organizers impacts specific groups of students. In particular students who have demonstrated a deficiency in their writing in the past.

We plan on sharing our research results with other members of our school community. Particularly with members of our staff science department, school improvement team, and school administrators. One of our school improvement goals at our school is to close the achievement gap in reading and writing between our top performing students and our bottom performing students. Our study suggests that utilizing graphic organizers can increase writing performance of students. 


\section{Chapter Two}

\section{Reflective Essay on MiTEP:}

\section{A Description of My MiTEP Experience}

I became involved with the Michigan Teacher Excellence Program (MiTEP) after learning about it at a Kalamazoo Public Schools secondary level science department meeting. I applied to the program in February of 2011 attended the first course, Earth Systems Institute I, in Houghton during the summer of 2011. The MiTEP program provided me with the rare opportunity to earn 20 graduate degree credits at no cost, work collaboratively with colleagues whom I normally did not work with, expand my leadership abilities, broaden my knowledge and application of research supported pedagogy in my classroom, and learn from professionals and experts in several earth science related fields. In addition the course work offered online allowed me to broaden and deepen my knowledge of earth systems and earth's history. This helped me to increase the rigor and relevance of the earth science courses I teach to high school students. 
The MiTEP program began in the summer of 2011 and ended after the summer of 2013, when I completed a 3-week internship at Pictured Rocks National Lakeshore. The two years in between were filled with online courses on earth science related subjects, science education, assessments, action research and another summer Institute at Michigan Tech's main campus in Houghton. My fellow cohort members and I also attended several professional development pedagogy days in Kalamazoo and Jackson facilitated by graduate students from Michigan Tech. These pedagogy days focused on strategies we could use to incorporate inquiry-based instruction into our teaching, developing lesson plans we could use in our classrooms, and preparing for presentations to develop our leadership opportunities at conferences such as the Michigan Science Teachers Association (MSTA) at Eastern Michigan University and the Geological Society of America (GSA) regional conference at Western Michigan University.

My experiences throughout the MiTEP program have had a profound impact on my teaching practices as a high school science educator. The program has changed the way I look at everything related to teaching and learning. I now think more critically about what I want my students to learn, how I can help them learn best, and how I can accurately and fairly assess what they have learned. I credit my time with the MiTEP program for helping me to get started on this journey towards becoming a more effective educator.

\section{How the MiTEP Program Influenced My Teaching}


The MiTEP program influenced my teaching in three major ways. First, the program exposed me to much more earth science content than I had ever been exposed to during my undergraduate coursework. Second, the program provided training in the development and use of inquiry-based instruction in the classroom which I have incorporated into my instruction. Finally, the MiTEP program allowed me to work with and collaborate with a large and diverse group of educators.

Prior to my involvement in the MiTEP program I had been teaching for 6 years at the high school level. The classes that I taught were almost exclusively ninth grade introductory biology courses. In my undergraduate course work for my teaching degree my science classes were mostly biology and chemistry centered. My only exposure to any earth science course was an introductory geology course. After learning I was accepted into the MiTEP program I approached the administration team at my school and requested an opportunity to teach earth science in addition to biology. My request was granted and as I began to prepare for that first earth science course in the fall of 2012 I quickly realized how little I knew about earth science topics and instruction. Thankfully the MiTEP program provided lots of opportunities for me to learn the earth science content necessary to successfully teach the course. Since that first earth science course I have taught four other earth science courses at my high school. Due to my exposure and experiences in MiTEP I have felt more and more comfortable and confident in my ability to plan meaningful, engaging earth science instruction for my students. One of the aspects I most appreciated about the course work as it related to earth science content was that it focused on the geology 
and earth systems of Michigan. This helped me make my instruction more relevant to my students.

Perhaps the greatest change in my teaching practices has been my use of inquiry-based instruction into my teaching repertoire. Many of the pedagogy days centered on inquiry-based instruction. We learned what inquiry was, how we could design lessons with varying amounts of inquiry, and about different ways to increase the inquiry in our classroom. One project I worked on a lesson study project based on an inquiry-lesson on porosity and permeability of ground water. I worked with two other members of my cohort, Alison Nelson \& Julie Young, to develop a structured inquiry activity that we adapted from a traditional lab activity provided by our textbook. This lesson provided students with an opportunity to engage in the inquiry process in a nonthreatening way and laid the groundwork for future inquiry. What I most liked about the project was the chance to collaborate with my peers about a topic we all teach. This collaboration helped us to develop a plan that could really meet the needs of our students. Without the opportunity to collaborate and share ideas the lesson would not have been nearly as successful. In addition to the power of collaboration, the other valuable aspect of the lesson study project was that I learned how to adapt almost anything from a traditional lab/classroom activity that would typically be teacher-driven into something that is more inquiry-based and studentdriven.

Meeting and working with a diverse group of dedicated educators was another way that MiTEP influenced and continues to influence my teaching. The MiTEP program provided an opportunity for me to work more closely with my fellow 
educators at Kalamazoo Public Schools, as well as educators from Jackson Public Schools, and Grand Rapids Public Schools. Working with dedicated teachers throughout this program was inspiring and motivational. Having the advantage to learn with and from teachers in a professional environment is not always something educators get to do. All too often teachers are left on an "island" to plan, teach, and assess student learning all on their own. The MiTEP program reminded me and more importantly provided me with plentiful occasions to learn from and with my colleagues. In addition to the Lesson Study Project, I was able to collaborate with Yonee Kuiphof during our internship program at Pictured Rocks National Lakeshore. While we were there we collaborated on a number of exciting projects. During the 2012-2013 school year I collaborated with two fellow teachers at Kalamazoo Central High School--James Wright \& Brytt Ergang--on an Action Research Project centered on how the use of graphic organizers can affect student writing. The information we gained from that research project continues to influence my instruction today. In addition to these major collaborative efforts the summer institute courses in Houghton and then in Kalamazoo \& Jackson during the first and second summer of the MiTEP program afforded daily possibilities to work with and learn from all the other teachers in the MiTEP program. I was especially grateful for the good fortune I had to work with teachers from other grade levels and from other school districts. I found that listening to their experiences and sharing some of mine was a very valuable and rewarding experience. I discovered that being around similarly minded educators was very invigorating for me as a teacher. Seeing other teachers innovate and stretch themselves professionally drove me to do the same. In addition expanding my 
network of peers gives me more resources and support in terms of advice, lesson ideas, and materials.

\section{How MiTEP Influenced Me as a Teacher Leader}

Before coming to the MiTEP program I already considered myself one of the leaders in my school community. I had served for several years as a freshmen academy team leader, I completed an "Aspiring Administrators Academy" hosted by the superintendent of the Kalamazoo Public schools, and I was a member of the school leadership team. However, none of those prior leadership experiences involved work centered on science teaching and learning.

The MiTEP program provided me with numerous opportunities to serve as a leader within a community of science educators. At first, I found myself hanging back and letting others lead during my time in MiTEP, but as I learned more I became more confident in myself and my ideas and more comfortable sharing ideas with my cohort. Soon, it became easy to take the lead on a project, and to feel confident in sharing my opinions and ideas with other teachers. A specific opportunity that came about as a result of the MiTEP program was the option I was given to present some of my work to a group of science teachers at the Michigan Science Teachers Association Conference. I shared my work developing a ground water model that uses local well $\log$ data. I found it to be a rewarding experience as it provided me with a chance to stand up in front of a group of fellow educators and inform them of a new science 
lesson that addressed required standards, was relevant to students' lives, and provided students with an opportunity to practice inquiry in their classroom.

This newfound confidence in myself as a teacher leader allowed me to serve as a leader for other teachers back at Kalamazoo Central. I felt more at ease sharing and discussing ideas for lessons and activities with other teachers. Soon, I noticed that I was getting asked for my thoughts and opinions about lesson ideas and activities from teachers noticed what I was doing in the classroom and liked what they saw. For example, as I got better at crafting inquiry-based lessons, two fellow earth science and biology teachers at my school would often ask how the lessons worked and if they could use the materials I developed. After a while, I began to share with them the things I developed without being asked. I feel that over the course of the last few years while I have been in the MiTEP program my colleagues at Kalamazoo Central have begun to see me as one of the leaders in the science department.

\section{MiTEP's Effect on My Knowledge of Science Education and Research}

The MiTEP program has had a significant effect on my knowledge of science education and research. In terms of my understanding and ability to apply current best practices as they relate to science education the MiTEP program has helped me in several ways. Several courses in the MiTEP program such as ED 5570 Lesson Study, and the ED 5602 Pedagogy, helped me to develop a better understanding of current best practices in science education such as inquiry driven instruction. These classes provided me with the ability to develop my own material for use in my classroom and 
through sharing with my fellow MiTEP members I received a new collection of learning resources I will be able to utilize in my classroom for years to come.

Other areas of study in the MiTEP program included ED 5850 Science Leaders Internship, ED 5730 STEM Learning Materials, and ED 5705 Action Research. These classes helped me realize that understanding how students learn is a valuable and ongoing scientific question that researchers all over the world are seeking to better understand. The action research project that I developed with two of my fellow colleagues at Kalamazoo Central High School provided me with a good understanding of how I could play a role in enhancing the education communities understanding of student learning. We conducted a study on the use of graphic organizers with reading materials on a student's ability to summarize accurately what they had read. I also got a lot out of ED 5730 Stem Learning Materials which focused on how to design and deliver scientific assessments that would accurately and fairly assess students understanding of the content they were expected to learn. Through this course I designed a concept map assessment that I could use to fairly assess my students understanding of some basic ocean floor features.

\section{Problems with the MiTEP Program}

It is hard to find very many areas of the MiTEP program which I found problematic. The program and all of its varied classes, pedagogy days, and projects on the whole were very helpful to me as an individual teacher. There are a few things however that I think should have been done differently or perhaps could be considered 
if another program similar to the MiTEP program is ever developed and launched in the future.

One area that the MiTEP program fell short in my opinion is its restriction to a focus of earth science topics. I understand the logic behind focusing on earth science in terms of the general nature of these topics as they relate to all the other sciences, but I often thought as I was participating in many of the MiTEP programs how great it would be if a similar program was developed for biology, chemistry, or physics teachers. Connecting teachers from those content areas with experts from their fields at the college level would be extraordinarily beneficial for those teachers just as it was for the earth science teachers who got the opportunity to interact with experts in the various fields of earth science.

Another area of the MiTEP program that I did not find helpful was the emphasis on the Earth Caches. The earth cache project we completed in the GE 5230 Earth Systems Institute I course was an interesting foray into non-traditional education, but it wasn't a project that I found useful as it related to my job. I definitely see the value of projects like these in creating awareness and educating the public in new and innovative ways, but the project did not impact me in any positive way. When I completed the ED5850 Science Leaders Internship at Pictured Rocks National Lakeshore part of the internship experience was to create another earth cache for a site of geological significance in the park. Again, this project was a worthwhile endeavor in terms of increasing public awareness and knowledge of important geological processes in our state but it had no real application for me. I feel that at least one of the earth cache projects should have been replaced with a project that would have 
resulted in something that could have been incorporated more directly into the public school curriculum, such as more inquiry-based laboratory activities that connected earth science content with the geology of Michigan, particularly near home. Often students fail to see the relevance of the earth science topics they are presented with to their own lives. This is an area that the MiTEP program could have focused even more on.

A final area for improvement was the use of the Pedagogy days. In the beginning of the program the pedagogy days were filled with activities and information that were both informative and useful. We focused on pedagogical practices that would be beneficial to students and even got the opportunity to develop lessons and activities we could use with our own students. I found that, as the program went on into its second year, the usefulness of the pedagogy days waned. As a teacher it can be difficult to take time out of my classroom but I was happy to do it when I knew it would result in something that would ultimately benefit my students. In the last couple of pedagogy days there was much time wasted and very little productive outcomes. On some of the days, the agendas could have been accomplished in a couple of hours, rather than taking up an entire day and removing me from the classroom for that time period.

\section{Conclusion}

While far from perfect, the MiTEP program allowed me an opportunity grow in so many ways as an educator. I was able to expand my knowledge of important earth science content. The program connected me with my peers in a new and 
rewarding ways. It provided me with an opportunity to expand and re-imagine my role as a leader in my educational community. The MiTEP program also connected me with scientists at the university level. This helped me better connect current research and understandings in the scientific community to the content I teach in the classroom. Finally, participating in this project allowed me to contribute in some small ways to the scientific communities understanding of quality teaching and learning.

I feel privileged to have been a part of this MiTEP program. I have worked with a wonderfully diverse group of people who care deeply about the state of science education. I know that my experiences while participating in this program were unique and once-in-a-lifetime experiences that have and will continue to have a positive impact on my teaching career. I often talk about my experiences with the MiTEP program to others and I always feel a little guilty that I was able to experience this program and they did not. I would love to see this kind of program developed further and expanded to other disciplines because I see how beneficial it has been for me and my students, and I would love to see other teachers benefit from a program similar to this one. 


\section{References}

Collins Writing Program. (n.d.). Retrieved November 22, 2014, from http://www.collinsed.com/research.htm.

Gil-Garcia, A., Villegas, J. (2000). Engaging Minds, Enhancing Comprehension and Constructing Knowledge through Visual Representations. Presented at Word Association for Case Method Research.

Hall, T., \& Strangman, N. (n.d.). Graphic Organizers $\mid$ National Center on Accessible Instructional Materials. Retrieved November 22, 2014, from http://aim.cast.org/learn/historyarchive/backgroundpapers/graphic_organizers\# .VHC-HfnF-So

Ozmen, Ruya (2011). Comparison of Two Different Presentations of Graphic Organizer in Recalling Information in Expository Texts with Intellectually Disable Students. Educational Sciences: Theory and Practice, volume 11, no. 2, pages 785-739. 